
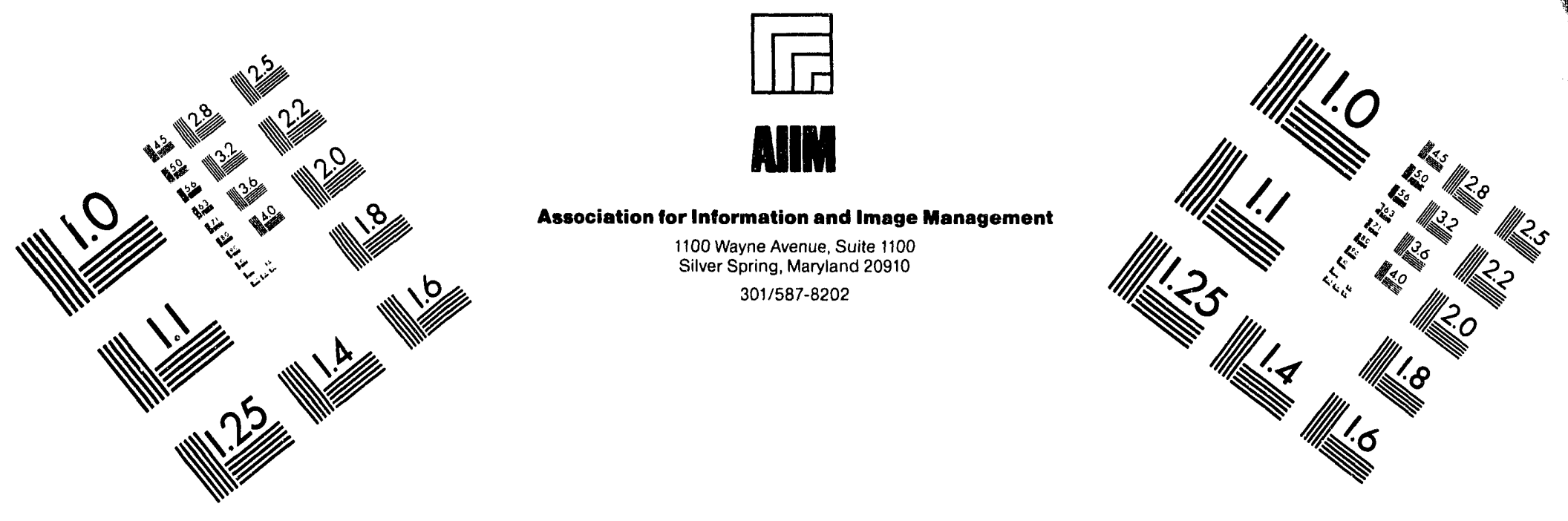

\title{
Centimeter
}

$\begin{array}{llllllllllllllll}1 & 2 & 3 & 4 & 5 & 6 & 7 & 8 & 9 & 10 & 11 & 12 & 13 & 14 & 15 & \mathrm{~mm}\end{array}$

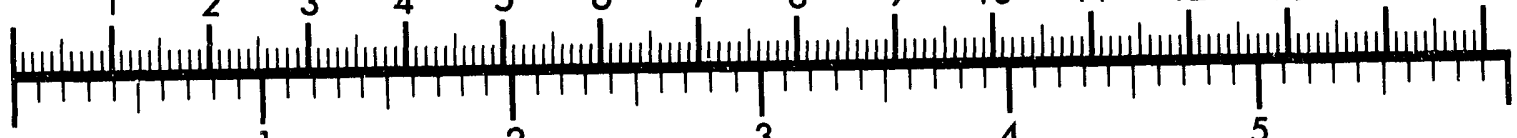
Inches
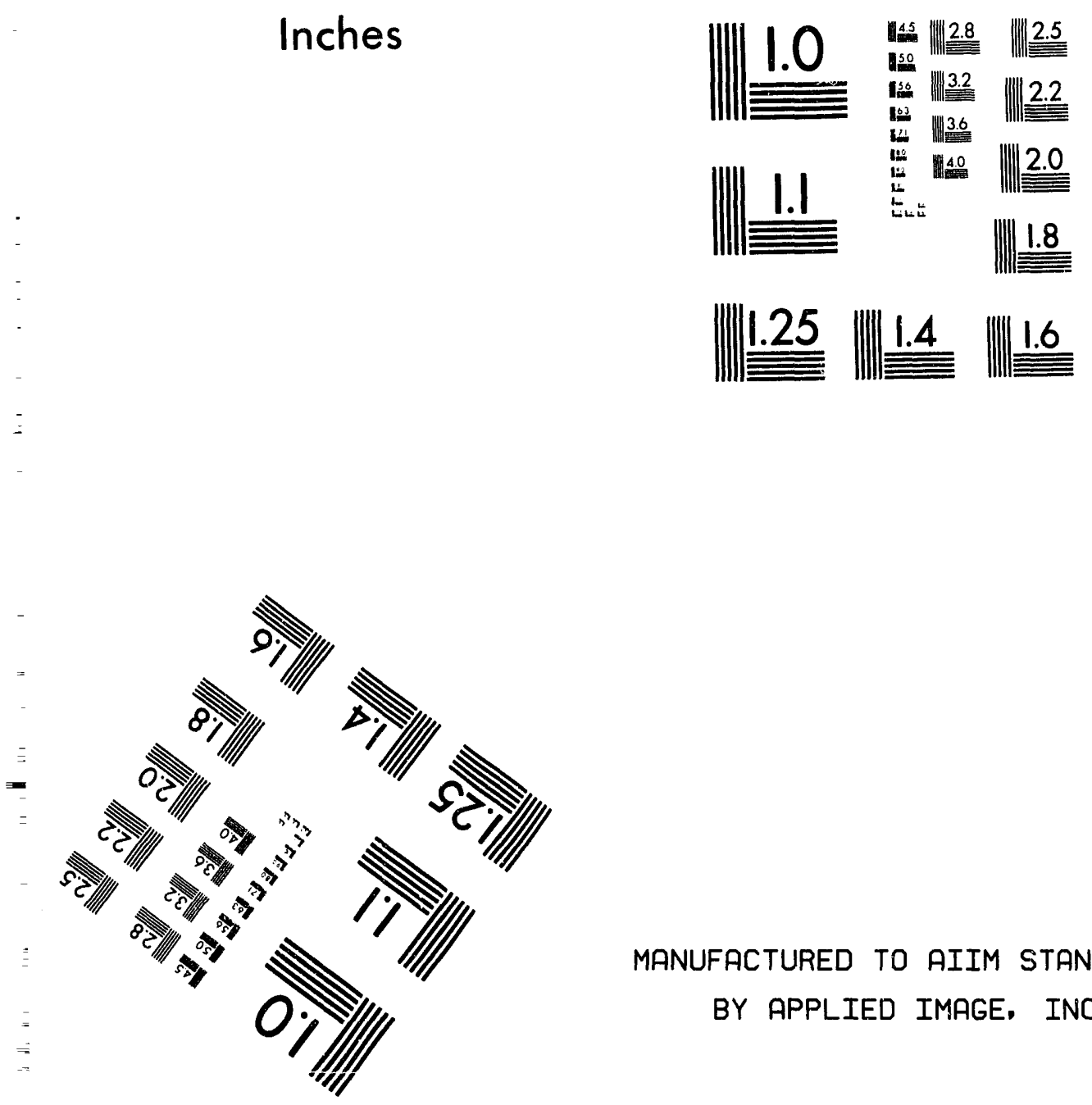

MANUFACTURED TO AIIM STANDARDS BY APPLIED IMAGE, INC.

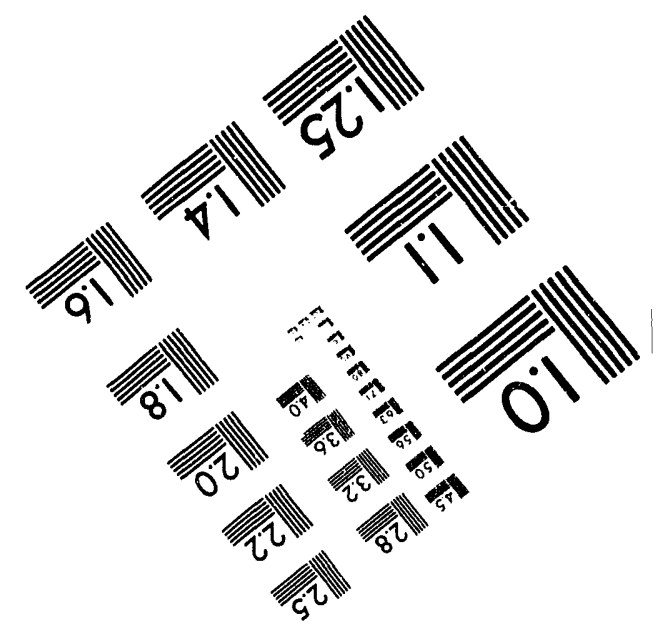



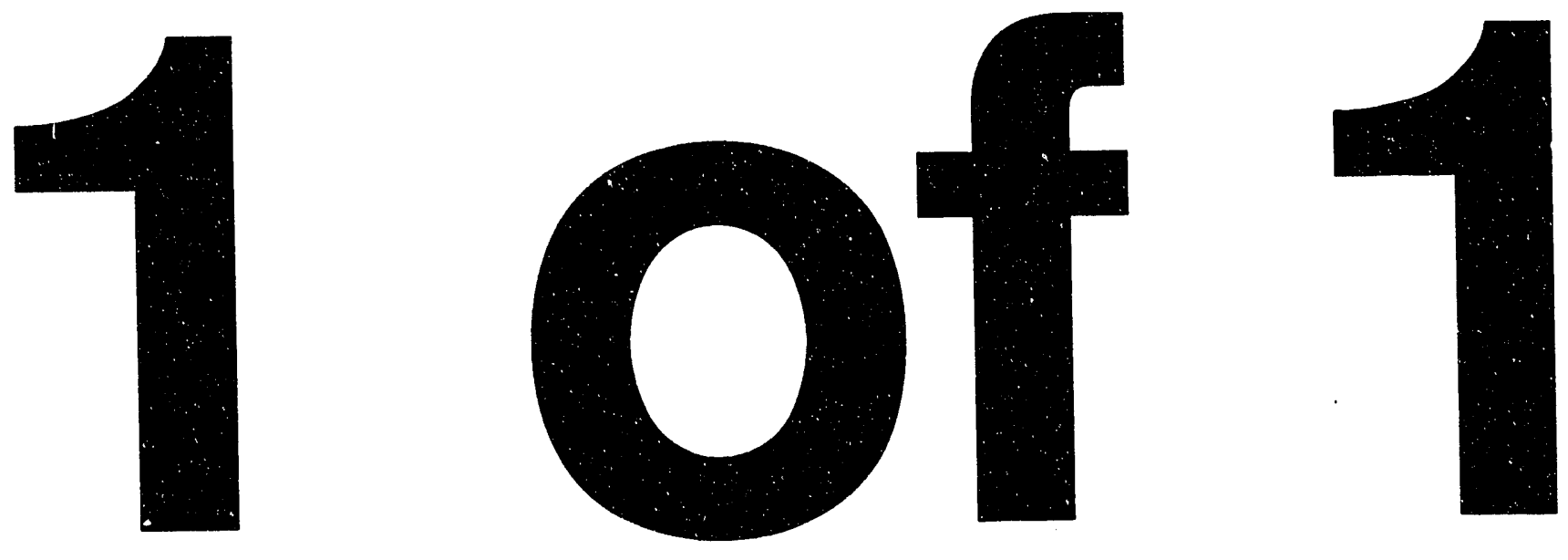


\section{PROGRESS PERFORMANCE REPORT}

Project Title:

Grant Number:

Grant Period:

DOE Project Officer:

Principal Investigator:

Research Organization:

\author{
Photochemical Dynamj.cs of \\ Suræace Oriented Molecules
}

DE-EG02-91ER14205

$8 / 0: / 92-7 / 31 / 93$

Wil-iam H. Kirchhoff

Eunäamentàl Interactions Branch

Division of Chemical Sciences

Department of Energy

Wilson Ho

Telephone: (607)255-3555

FAX:

(607) $255-6428$

e-mail: wilsonho@msc.cornell.edu

Department of Physics

Correll University

Ithaca, New York 14853-2501

\section{DISCLAIMER}

This report was prepared as an account of work sponsored by an agency of the United States Government. Neither the United States Government nor any agency thereof, nor any of their employees, makes any warranty, express or implied, or assumes any legal liability or responsibility for the accuracy, completeness, or usefulness of any information, apparatus, product, or process disclosed, or represents that its use would not infringe privately owned rights. Referprocess disclosed, or represents that its use would not infringe privately owned trade name, trademark, manufacturer, or otherwise does not necessarily constitute or imply its endorsement, recommanufacturer, or otherwise dhe United States Government or any abency there/t. The views and opinions of authors expressed herein do not necessarily state or ietlect those of the United States Government or any agency thereof. 
TABLE OF CONTENTS

$\underline{\text { Page }}$

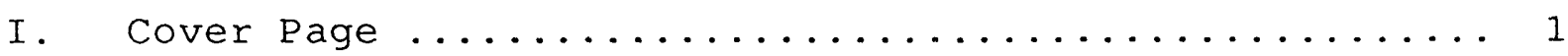

II. Summary of Overall progress $\ldots \ldots \ldots \ldots \ldots \ldots \ldots \ldots \ldots$

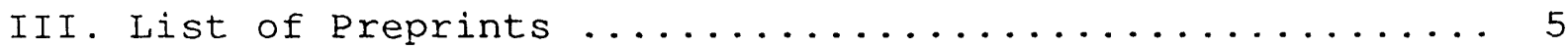

IV. Summary of Work to be Performed During the succeding

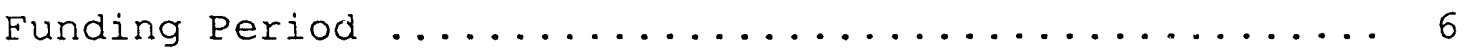

V. Budget summary $\ldots \ldots \ldots \ldots \ldots \ldots \ldots \ldots \ldots \ldots \ldots \ldots \ldots \ldots$

VI. Statement of Estimated Residual Funds at the End of the Current Funding Period ................. 9

VII. A set of Preprints .................... 10 


\section{SUMMARY OF OVERAIL PROGRESS}

The period $8 / 01 / 92$ - 7/31/93 constitutes the second year of a new project titled "Photochemical Dynamics of Surface Oriented Molecule". During this period, efforts have been concentrated in carrying out experiments to investigate the dynamics of surface photochemistry and to construct the apparatus specifically designed for the DOE project. Four papers were submitted for publication: three to the Physical Review Letters and the fourth is an invited review paper for a special issue of surface science commemorating the first 30 years of publication of the journal.

Measurement of the translational energy distribution of desorbed molecules is an important and often used approach to obtain information on the dynamics of surface reactions. It is found that in many systems the distribution is fit well with a Maxwell-Boltzmann functional form. However, no explanation is provided and the fitting is used to extract a temperature which is compared to that of the substrate. We have succeeded in providing a-theoretical justification based on a simple physical model for the validity of the widely used Maxwell-Boltzmann functional form for the time-of-flight measurements.

The dynamics of photodesorption and photoreaction was investigated by using a mass spectrometer to detect molecules desorbed with nanosecond and femtosecond laser irradiation. The system we have chosen is $\mathrm{O}_{2}$ alone and coadsorbed with $\mathrm{CO}$ on Pt (111) at $80 \mathrm{~K}$. Pump-probe experiments reveal that desorption of $\mathrm{O}_{2}$ continues for a duration of $1 \mathrm{ps}$, indicating that the 
photochemical mechanism involves multiple excitation of adsorbed $\mathrm{O}_{2}$ by photogenerated hot electrons. This charge-transfer process proceeds for about 1 ps after the laser excitation. The excitation process has a highly nonlinear dependence on the incident laser fluence.

In a separate series of experiments, it is found that the branching ratio of a surface reaction is altered as the excitation laser pulse duration decreases from about 7 nanosecond to 150 femtosecond. The branching ratio for $\mathrm{O}_{2}$ desorption to $\mathrm{CO}_{2}$ product formation increases as the $\mathrm{O}_{2}$ is photoexcited by femtosecond light pulses, in contrast to the larger $\mathrm{CO}_{2}$ photoyield for nanosecond laser excitation. This difference in the reactivity is attributed to the rate of photoexcitation and consequentiy the time scale for the reactants to remain in the excited states. These results demonstrate the influence of dynamics on the distribution of reaction products.

A review paper tracing a personal overview of the historical development of modern surface photochemistry was written in response to an invitation to contribute to a special volume of Surface science to commemorate the 30 years since the first publication of the journal. The topic of surface photochemistry was chosen by the committee involved in the publication of this special issue as one of the seven "Frontiers of surface scence", along with scanning tunneling microscopy, atomic force microscopy, surface science at low temperatures, and the development of surface science in China. 


\section{IIST OF PREPRINTS}

1. "The Effect $c \equiv$ Excited State Quenching on Velocity

Distributions of Photodesorbed Species", F.M. Zimmermann and W. Ho, submitzed to Phys. Rev. Lett.

2. "Femtosecond -aser Desorption of Molecularly Adsorbed Oxygen from Pt (111)", F.-J. Kao, D.G. Busch, D. Cohen, D. Gomes da Costa, and w. Ho, submitted to Phys. Rev. Lett.

3. "Eemtosecond :ersus Nanosecond Surface Photochemistry: $\mathrm{O}_{2}+\mathrm{CO}$ on Pt (111) at $80 \mathrm{K"}$, F.-J. Kao, D.G. Busch, D. Gomes da Costa, and $W$. Ho, slizmitted to Phys. Rev. Lett.

4. "Surface Photzchemistry", W. Ho, submitted to surf. Sci. 


\section{SUMMARY OE WORK TO BE PERFORMED DURING THE SUCCEEDING FUNDING PERIOD}

The results obtained to-date suggest a series of experiments which are in the direction of the original DOE proposal. We will continue the comparison of nanosecond vs. femtosecond pulse laser excitation surface photochemistry. The new apparatus is expected to be completed in about two weeks and is especially designed to carry out time-of-flight distribution measurements of the photodesorbed molecules. In addition, the angular distribution of the photoyield will be measured. The apparatus is also optimized for pump-probe investigation of the time scales involved in surface photochemistry by mass spectrometry of the photodesorbed molecules and second harmonic generation spectroscopy of the evolution of the surface due to the photochemistry.

The desorption of Co from $\mathrm{Cu}(111)$ and the photodissociation of $\mathrm{Mo}(\mathrm{CO})_{6}$ on $\mathrm{Cu}(111)$ to yield $\mathrm{CO}$ as the photodesorbed molecule will be investigated first with the new apparatus. These experiments will be followed by studies on the photochemistry of $\mathrm{O}_{2}$ coadsorbed with $\mathrm{CO}$ on $\mathrm{Pt}(111)$ and $\mathrm{Ag}(110)$ at $30 \mathrm{~K}$. A comparative study will be made between photodesorption of $\mathrm{CO}$ on metal surfaces, $\mathrm{Cu}(111)$ and $\mathrm{Ag}(110)$ and a semiconductor surface, Si(100)2x1, yielding insights into the role of the substrate in the quenching, energy transfer, and charge transfer and exchange involving the photoexcited molecules. 

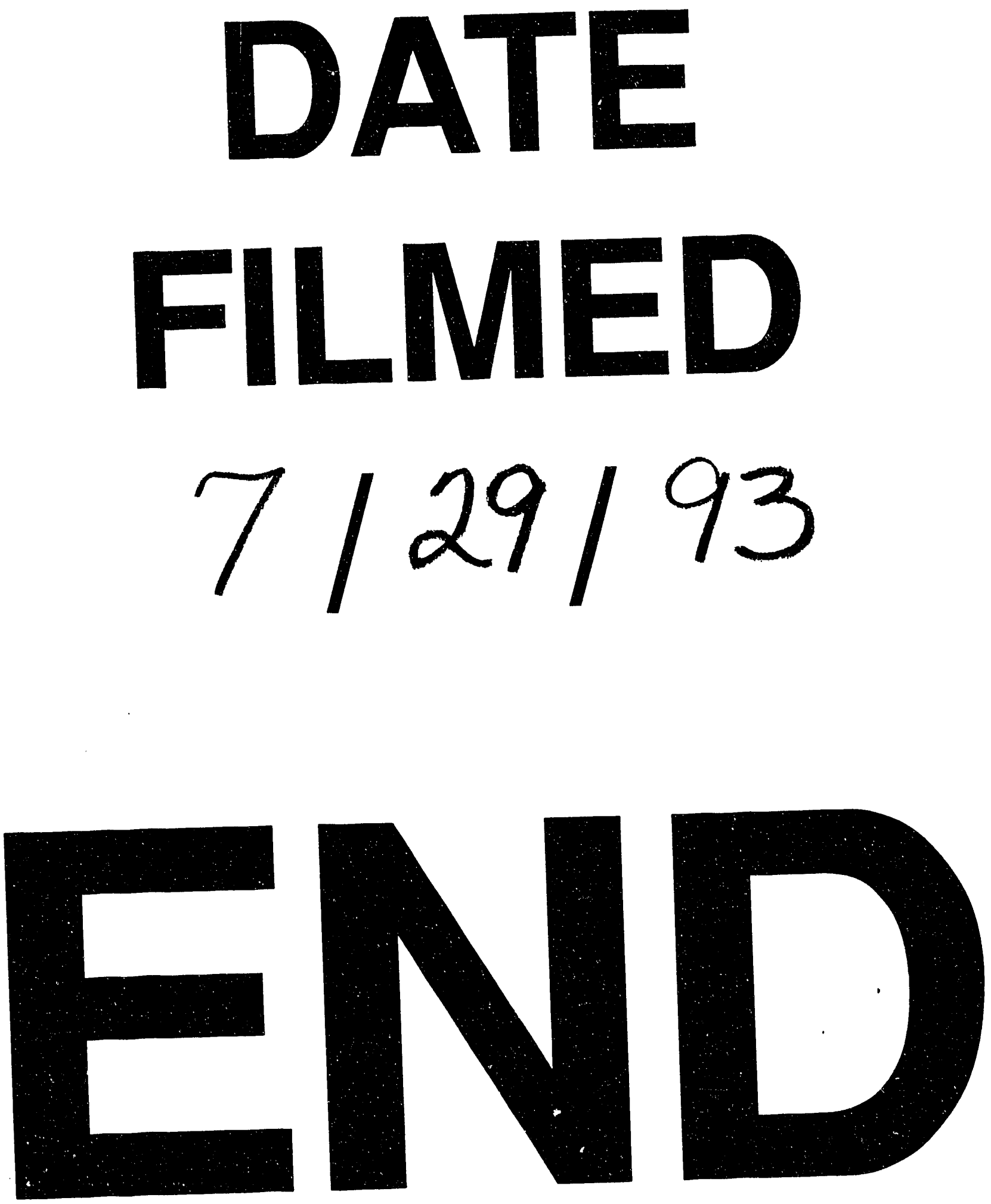
